\title{
ARTICLE
}

\section{Social bonding in diplomacy}

\author{
Marcus Holmes ${ }^{1 \star}$ (D) and Nicholas J. Wheeler ${ }^{2}$ \\ ${ }^{1}$ Department of Government, William \& Mary, Williamsburg, VA 23185, USA and ${ }^{2}$ Department of Political \\ Science and International Studies, Institute for Conflict, Cooperation and Security, University of Birmingham, \\ Birmingham B15 2TT, UK \\ *Corresponding author. Email: mholmes@wm.edu
}

(First published online 13 November 2019)

\begin{abstract}
It is widely recognized among state leaders and diplomats that personal relations play an important role in international politics. Recent work at the intersection of psychology, neuroscience, and sociology has highlighted the critical importance of face-to-face interactions in generating intention understanding and building trust. Yet, a key question remains as to why some leaders are able to 'hit it off,' generating a positive social bond, while other interactions 'fall flat,' or worse, are mired in negativity. To answer, we turn to micro-sociology - the study of everyday human interactions at the smallest scales - an approach that has theorized this question in other domains. Drawing directly from US sociologist Randall Collins, and related empirical studies on the determinants of social bonding, we develop a model of diplomatic social bonding that privileges interaction elements rather than the dispositional characteristics of the actors involved or the material environment in which the interaction takes place. We conclude with a discussion of how the study of interpersonal dyadic bonding interaction may move forward.
\end{abstract}

Keywords: diplomacy; sociology; micro-sociology; psychology; social bonding; face-to-face interaction

\section{Interrogating the 'Human Factor'}

It is widely recognized among state leaders and diplomats that personal relations play an important role in international politics. The 'human factor' has been cited as one of the key ingredients for overcoming long-standing interstate hostilities. As the former Soviet leader Mikhail Gorbachev said of his relationship with US President Ronald Reagan in front of the Politburo in 1987, 'we clearly realized how much the human factor means in international politics... These people are guided by the most natural human motives and feelings' (quoted in Matlock 2005, 271). Former British Prime Minister Margret Thatcher felt similarly upon meeting with her Soviet counterpart in 1984, famously saying, 'I like Mr. Gorbachev, we can do business together.' In the aftermath of the historic nuclear accord signed by the E3 +3 and Iran in July 2015, US Secretary of State John Kerry described his relationship with his Iranian counterpart Mohammad Javad reproduction in any medium, provided the original work is properly cited. 
Zarif in the following way: 'We were both able to approach these negotiations with mutual respect, even when there were times of heated discussion. And - he would agree with me - at the end of every meeting we laughed and we smiled and we had the conviction that we would come back and continue to process. ${ }^{.1}$ More recently, U.S. President Donald Trump suggested a crucial reason for pursuing diplomacy with North Korean leader Kim Jong-Un: 'I'd probably have a very good relationship with $[\mathrm{him}] .^{.2}$ Positive personal relationships, and the prospects of them developing, can seemingly pay significant dividends.

Yet, for every relationship where leaders form important bonds of understanding and connection with each other, there appear to be as many where the opposite is true. Examples of dyadic leader relationships where mistrust, suspicion, and hostility abound are ample. Whereas 30 years ago at the height of the Cold War, Gorbachev and Reagan were able to develop trust at the interpersonal level, and as a result settle state-level differences (albeit temporarily), the personal relationship between Putin and Obama was one mired in distrust and hostility. Social bonds can be both positive and negative in nature.

In this paper, we argue that variation in the outcome of face-to-face interactions and development of interpersonal social bonds is explained by the qualities of the social process of the interaction itself. We conceptualize a social bond as either the experience of 'personal chemistry,' 'hitting it off,' or other form of positive emotional energy, or the adverse experience of negative energy or, in the worst cases, domination. Drawing from micro-sociological theory, especially the work of the US sociologist Collins (2004), and subsequent elaborations of his theory and related empirical studies on the determinants of social bonding, we develop a model of diplomatic social bonding that focuses on interaction elements, though does not ignore, the dispositional characteristics of the actors involved or the material environment in which the interaction takes place. In particular, inspired by the work of Collins, we suggest four conditions required for the development of a positive social bond: bodily co-presence, barriers to outsiders, mutual focus of attention, and shared mood. We expect that in the absence of any of these conditions a social bond will not form at all, or a negative emotional connection will engender, affecting how leaders negotiate and relate to one another.

We contribute to growing recognition over the last several decades in International Relations (IR) scholarship that interpersonal relationships that Gorbachev and others have identified as crucial are indeed important variables to systematically investigate. The intuition is simple: at the end of the day, international politics is conducted by, and between, individuals who bring their own beliefs, emotions, sensibilities, traits, and dispositions to the negotiating, decisionmaking, and even dining tables. Outcomes are not determined solely by the distribution of power, intensity of national interests, existence of institutions, or norms. Rather, existing studies suggest that individual leader characteristics, and crucially the interactions between those leaders, matter for outcomes. Further, unlike one-off transactions, the development of interpersonal relationships, such as those between competitors or enemies, often relies on iterative personal interactions. Reagan and

\footnotetext{
${ }^{1}$ The Telegraph, 15 July 2015.

${ }^{2}$ https://twitter.com/PressSec/status/952405070955544576.
} 
Gorbachev met face-to-face at four summits between 1985 and 1988, resulting in a chain of interactions where they both continued the work they had started and negotiated from positions crafted in previous meetings. Through this, they appreciated that there was ground for mutually beneficial cooperation, and most importantly, from this process of personal connection, they developed a relationship of trust that led to a transformation of the previous enmity that had prevailed at the state-to-state level (Wheeler 2018). ${ }^{3}$ A positive social bond ensured that the Cold War ended with a whimper, rather than a bang. In investigating why interpersonal interactions often result in better intention understanding and the development of trust, scholars have identified a number of important necessary conditions and processes. For example, face-to-face interaction has been identified as particularly important for building empathy and increased intention understanding (Holmes 2013, 2018). Empathy and intention understanding are, in turn, necessary conditions for leaders to build trust through a process of interpersonal bonding (Wheeler 2018).

These existing studies, while important for identifying the crucial processes occurring in personal interactions that may matter for outcomes, have thus far been unable to predict a priori when two individual policymakers or leaders are likely to undergo a process of social bonding. That is, face-to-face interactions do not always result in positive social bonds between two individuals. Another Cold War interaction, the rather infamous 1961 Vienna Summit between US President John F. Kennedy and First Secretary of the Communist Party, Nikita Khrushchev, is instructive. Kennedy admitted after the summit meeting that Khrushchev had 'just beat the hell out of me' (quoted in Reynolds 2009, 206). While they did learn about each other's intentions ('our views contrasted sharply... at least we knew better at the end where we both stood' (Kennedy 1961)), increased intention understanding at the summit did not lead to the development of a positive bond (see Holmes 2018). If anything, Kennedy left the interaction feeling dominated, bonded to Khrushchev through negative energy, an outcome which likely contributed directly to his comment to the New York Times journalist James Reston that a 'cold winter [lies] ahead.' What is more, there is strong evidence that Khrushchev's domination of the inexperienced Kennedy at the summit played a significant role in the Soviet leader's bold opportunistic move to deploy nuclear missiles to Cuba (Kempe 2011). The resulting crisis bringing the world the closest it has come to global nuclear war.

Therefore, face-to-face interactions, and the intention understanding that can result from them, are not necessarily an unalloyed good; less salutary effects sometimes occur. Consequently, it remains difficult to know when policymakers, diplomats, or state leaders will hit it off or when their interactions will be mired in negativity and a lack of personal connection. To address this puzzle, we take variation in the ebb and flow of interpersonal diplomatic interactions, specifically

\footnotetext{
${ }^{3}$ We define a personal relationship in the following way. 'Two people are in a relationship with one another if they impact on each other, if they are interdependent in the sense that a change in one person causes a change in the other and vice versa' (Kelley et al. 1983). In contrast, we conceptualize interaction as a social encounter that need not result in a change in one or both actors. We suggest that all relationships are forms of interactions, but not all interactions reach the level of sociality and interdependence required for a relationship.
} 
variation in social bonding, as the phenomenon to be explained. Rather than investigating the effects of personal bonds, such as 'bonding trust' defined by the absence of risk calculation (Wheeler 2018), we seek to understand what causes the bond to develop, or not, in the first place. What is this 'human factor' that Gorbachev described, or the 'personal chemistry' that Secretary George Shultz saw between Reagan and Gorbachev, or the social domination felt by President Kennedy? And, why does this elusive spark sometimes flash and other times remain mysteriously absent?

Social theorists, sociologists, and psychologists have been interested in such questions for centuries, though the tools and technology required to systematically investigate them with methodological precision have only recently been developed. And these methods are beginning to bear fruit. Drawing from decades of theorizing, and utilizing these methodological advances, we develop a theory of what we call interpersonal dyadic interaction. We conceive of social bonding as an emergent property of face-to-face interpersonal dyadic interaction that does not reduce to either of the individuals or their characteristics. ${ }^{4}$ The interpersonal is composed of individuals, and it takes place among individuals, but the process of interaction and the result engendered, both transcend individuals and, we argue, are integral to explaining the success or failure of interpersonal diplomatic interaction. Put simply, our argument is that it is not just variation in who the leaders are that matters, but rather variation in how they interact. Crucially, however, our argument is not that the environment, dispositions, or structural situation do not matter. As we detail below, power, interests, positions, domestic politics, and so on, are all relevant; indeed, simply getting two leaders into the same room to talk can often involve an aligning of constellations that implicate many of the traditional variables scholars of foreign policy analysis and diplomatic studies have investigated. At the same time, however, we do argue that these variables alone cannot account for the development or non-development of a social bond between leaders. Such bonds do not reduce to material or even ideational considerations alone, but also represent emergent properties of the interactions themselves. As such, our argument complements many existing studies of foreign policy and diplomacy that focus on the enabling conditions of diplomacy; our focus, however, is on what happens once leaders enter the negotiating room. Finally, our main interest here is in reassurance diplomacy, where states have struggled to signal their intentions to one another through other means, but for reasons we elaborate below, the model we create is applicable to diplomacy between allies and enemies alike, though some of the specific operationalization of the variables will differ.

In building this theory we draw from two main schools of thought on interpersonal interaction. First, we interrogate dramaturgical sociological approaches that began with Durkheim and Tarde, were reinvigorated by Goffman, and brought into the contemporary context by Turner and Collins to theorize the individual

\footnotetext{
${ }^{4}$ While there are many perspectives on the concept of emergence in the sciences, we conceptualize it here as the result of interactions of the units that arise because aggregations have collective properties that the units lack. For example, human memory is an emergent property of complex interactions between the brain's differentiated cells with no single cell possessing memory. Explaining memory by appealing to the properties of a single cell commits the fallacy of division.
} 
components of social bonding and the emergence of a social bond. Sociology has long been interested in the 'micro-sociology' of human interactions. ${ }^{5}$ As Collins $(2004,3)$ argues, 'microsociology is the key to much that is larger...the here-and-now of face-to-face interaction, is the scene of action and the site of social actors. If we are going to find the agency of social life, it will be here.' For Collins $(2004,259)$, ' $[\mathrm{m}]$ icro-situational encounters are the ground zero of all social action and all sociological evidence. Nothing has reality unless it is manifested in a situation somewhere.' Micro-sociology not only theorizes what social bonds are in the ontological sense - that is, identifying what does or does not constitute a social bond - but also identifies the conditions necessary to create one. Yet, such theorizing is often abstract and can be difficult to operationalize in order to create testable theory. We therefore combine micro-sociological theory with empirical evidence drawn from a variety of eclectic and dynamic sources, such as 'speed dating' studies, in order to derive the conditions under which interpersonal social bonding obtains. From these investigations, we derive testable propositions regarding social bonding in diplomacy and conclude with discussion of the limitations of the model, ramifications, and ideas for empirical investigation.

\section{Individuals and interpersonal interaction}

While the intuition that individuals and interpersonal interactions among leaders, diplomats, and policymakers can make quite a difference to political outcomes is hardly a new insight in the field of IR, receiving significant attention in diplomatic studies, foreign policy analysis, practice theory, and decision-making analysis through much of the $20^{\text {th }}$ century (Nicolson 1939; Rosenau 1966; Derian 1987; Berridge 1995; Jönsson and Hall 2005; Sharp 2009; Pouliot 2010; 2016; Adler and Pouliot 2011; Rathbun 2014; Sending, Pouliot, and Neumann 2015; Trager 2017), the systematic and interdisciplinary study of the effects of interpersonal interactions by political scientists is relatively recent. ${ }^{6}$ For example, the move to incorporate findings from psychology and social neuroscience as a way to uncover the micro-foundations of political interaction and causal mechanisms of decisionmaking has lagged behind other disciplines, such as economics, which has long been interested in using the brain to identify mechanisms (Holmes 2014; Kertzer and Tingley 2018).

One reason for this lack of engagement, relative to its peer disciplines, has been the dominance of structural-level and institution-focused theorizing. Whether Kenneth Waltz's $(1959,1979)$ relative dismissal of the first image as reductionist in neorealism, Robert Keohane's (1984) focus on the effects of aggregation in institutions in neoliberalism, Alexander Wendt's (1999) state-centric constructivist response to both, or recent work 'beyond anarchy' focusing on hierarchical or heterarchical political structures (Mcconaughey, Musgrave, and Nexon 2018), IR

\footnotetext{
${ }^{5}$ Micro-sociology has been referred to as a 'science of communications,' which includes elemental sociology, wherein the 'basic modalities of interaction produced both at a distance and in face-to-face situations' are objects of inquiry (Tonkonoff 2017, 7).

${ }^{6}$ This is not to say that early diplomacy research is at all simplistic or naive of causal mechanisms and inference. See Ross (2014), for example, on the nuanced understanding classical realists such as Morgenthau and Niebuhr had regarding the interaction between emotion and change.
} 
has traditionally tended to focus on the second and third images, rather than the first (Solomon and Steele 2017). Structural and institutional theories, by their nature, downplay the scope for any particular individual - be she a leader, policymaker, or diplomat - or dyadic relationships between individuals, in favor of larger, more powerful forces, such as state power or the effects of institutional regimes or norms. As Rathbun $(2014,13)$ observes, individuals generally are often conceived as being 'epiphenomenal to power,' along for a ride in a vehicle they have little control over. However, the end of the Cold War served as a particularly salient moment for IR theory. It led to a reexamination of assumptions and approaches, opening the door for a re-imagining of the role that diplomacy and other 'reductionist' approaches might play alongside structural forces (Bjola 2013). ${ }^{7}$ As Solomon and Steele $(2017,267)$ observe, 'there is continuing broad dissatisfaction with grand or structural theory's value without "going down" to "lower levels" of analysis where structures are enacted and contested.'

Investigation of how individuals affect outcomes has occurred in at least three broad domains. These are not necessarily divided by a clear bright line, as each domain is diverse, dynamic, eclectic, and interweaves with the others, thereby resisting simplistic framing and categorization, but the broad contours are fairly distinct: first, the causal power of dispositions, traits, personality, and experiences of leaders and diplomats; second, the relevance and nature of leaders' beliefs and emotions in decision-making; and, third, the interaction between leaders in diplomacy, either in dyads, mediated triads, or larger groups. A starting point for all three of these domains is the observation that differences among individuals, and the ways in which they interact, can be connected to the types of dependent variables that often dominate our analyses. As Byman and Pollack (2001, 109), in summarizing the need to refocus attention on state leaders, observe: 'the goals, abilities, and foibles of individuals are crucial to the intentions, capabilities, and strategies of a state.'

With respect to the first domain of unpacking particular leader dispositions, traits, and experiences, scholars have focused on understanding how each of these characteristics affect decision-making and relations more generally. Horowitz et al. (2015) demonstrate that the background of leaders, particularly as it relates to early experiences, has an effect on the willingness to enter war. Saunders (2011) similarly finds leader experience and beliefs have important causal effects on decisions to intervene. Traits and dispositional capacities also matter significantly when it comes to negotiation and conflict resolution. For instance, Holmes and Yarhi-Milo (2017) show that a particular dispositional trait, empathic capacity, and the ability to convey empathy to others, are both critical to the process and outcome of peace summits. Proclivities toward anger or outrage may increase the likelihood of rapid emotionally-fulfilling retaliatory action (Hall 2017). And variation in more subtle dispositions, such as the ability to 'self-monitor' one's

\footnotetext{
${ }^{7}$ One important exception to this general trend has been the English School, in which diplomacy has long played an important role, much of which predates the end of the Cold War, though it has tended to be conceived within English School theorizing in more structural terms, with the interpersonal relationships between diplomats and state leaders very much a secondary consideration (see Wheeler 2013 for a discussion of this lacuna in English School theorizing).
} 
overt emotional and expressive behavior, may explain why particular leaders are willing to pay a high cost in order to defend their reputation for resolve (Yarhi-Milo 2018). To the extent that this domain has investigated leader relationships with one another, it tends to be done in an additive way: the right combination of personality characteristics and beliefs added together explain outcomes. For example, the positive Reagan-Gorbachev relationship referenced above is often explained by doubling down on personality characteristics and idiosyncratic personal beliefs. As Breslauer and Lebow $(2004,183)$ put it, 'Confronted with a different general secretary, who had neither Gorbachev's personality nor his commitment to reduce the nuclear threat, Reagan might have remained an anti-Soviet ideologue.' Put another way, the sum of the parts resulted in a particular outcome.

One issue with this approach to individuals is that, as Jervis (2013) notes, it is difficult to isolate specific traits and dispositions among a litany of other relevant individual-level variables. Further, dispositions, such as self-monitoring, and beliefs, developed perhaps through experience, interact not only with one another, but also with the structural environment itself. Beliefs and dispositions therefore not only may evolve and change over time, often as a result of interactions individuals have with one another, but also make it difficult to isolate the causal effect of any one variable in a given decision. A further challenge to this domain of individual-level research is the extent to which leader decision-making is affected not only by a leader's traits, but by the same variables in other leaders as well. The dyadic interplay between traits, between a leader with a disposition toward rage and another with high empathic capacity, for example, suggests a complexity that is difficult to sort out, often leading to the unsatisfying conclusion that one can study individuals qua individuals, while knowing that ultimately it may be the interaction between those leaders that are at least as important as individual-level traits.

A second domain of individual-level research has focused on the interplay between beliefs and emotions. Long eschewed as the realm of irrationality, emotion is now understood as being intimately tied to rationality (McDermott 2004; Mercer 2005, Mercer 2010). As Mercer $(2005,94)$ argues, 'Emotion is necessary to rationality and intrinsic to choice... [it] precedes choice (by ranking one's preferences), [it] influences choice (because it directs one's attention and is the source of action), and [it] follows choice (which determines how one feels about one's choice and influences one's preferences).' Similarly, emotion can both constitute and strengthen rational beliefs. 'Emotional beliefs' (Mercer 2010, 2) are those where the belief is imbued with emotion to such a degree that it is possible for an actor to be certain beyond evidence. Other scholars have focused on similar processes, such as the development of affective attachments (Sasley 2010), which affect how flexible individuals are in decisions regarding particular objects. According to Sasley, the Israeli-Palestinian peace process cannot be fully understood without appeal to the emotional attachments to land, such as Yitzhak Shamir's attachment to the Land of Israel, that create inflexibilities in negotiation. This is not to argue that emotion always results in rational decisions. As Holmes (2015) argues, emotion can both strengthen rationality as Mercer argues, or hamper it by producing behavioral responses that belie rational beliefs. The development of intuitions, 
automaticity, habits, and other emotional mental states that sit alongside beliefs and motivate behavior further complicate the decision-making process and are just now beginning to be fully analyzed and appreciated. ${ }^{8}$ The upshot is that emotion, and the experience of emotion, does not always lead to irrationality, but rather is an important part of rational decision-making and can make individuals quite sure about their personal beliefs.

Here too, however, a similar problem emerges in that this domain of research on the interaction between emotion and rationality has tended to focus on processes that occur within individuals, such as their physiological responses, and not on that which occurs between individuals. This is perhaps justified given the inherent difficulties of viewing emotion as a social phenomenon that can transcend individual human bodies (see Hutchison and Bleiker 2014), yet the result is that the study of emotion in IR and foreign policy analysis has tended to be monadic rather than dyadic - yet it studies a world where individuals interacting with one another often shapes outcomes.

Finally, the third domain of investigation has attempted to address some of these concerns by focusing on a particular form of international political practice involving leaders, diplomats, and other decision-makers: interpersonal interaction. Taking a cue from Wendt's symbolic interactionism in first encounters, scholars have investigated and debated the ways in which intentions may be communicated, empathy developed, and trust engendered through interactions between individuals who may have not interacted directly before. Holmes $(2013,2018)$ argues that face-to-face diplomacy is a discrete form of interpersonal interaction that allows for the transmittal of specific intentions between individuals, facilitated by neurological architecture evolved to aid intention understanding, thus overcoming a pernicious aspect of the security dilemma that emerges because of the alleged unknowability of intentions. This ability to credibly communicate intentions between individuals through interpersonal interaction represents a relatively thin version of empathy, defined as the ability to understand and experience the cognitive (e.g. intentions) and affective (e.g. emotions) mental states of others. ${ }^{9}$ Yarhi-Milo (2014) similarly focuses on the ability to assess intentions through personal assessments that are gathered through interaction, arguing that information gathered in interpersonal interaction can be particularly 'vivid' to policymakers and may be privileged in the assessment of intentions and decision-making. Wong (2016) focuses on what emotions, revealed in face-to-face interactions, communicate about actor intentions.

Empathy is arguably a necessary condition for the development of interpersonal trust. Trusting another requires the ability to first understand that interests might be potentially aligned (Head 2012). Wheeler (2013) argues that 'diplomatic

\footnotetext{
${ }^{8}$ There has been a proliferation of emotions research in IR in recent years. Bleiker and Hutchison (2008) and Hutchison and Bleiker (2014) provide a recent review of the literature. Particularly important for our purposes is the link between emotion and relations/practices (see Bially-Mattern 2011) as well as empathy (see Crawford 2014; Mercer 2014) and the neuroscientific findings that continue to refine our understanding the link between affect, emotions, and empathy (see Jeffery 2014). See also Ross (2014) and Hall and Ross (2015) for recent treatments.

${ }^{9}$ This division is more analytical than ontological since cognition and affect are intertwined and not separated by a bright line (see Mercer 2010; Holmes 2015).
} 
transformations' are possible when individuals are able to show empathy for their adversary's security concerns. Booth and Wheeler $(2008,7)$ term this 'security dilemma sensibility' (SDS). SDS refers to 'an actor's intention and capacity to... show responsiveness towards, the potential complexity of the military intentions of others. In particular, it refers to the ability to understand the role that fear might play in their attitudes and behavior, including, crucially, the role that one's own actions might play in provoking that fear' (Booth and Wheeler 2008, 7). SDS is crucially predicated on actors appreciating that others might - there can be no guarantees in an anarchic realm - be acting from a position of fear and insecurity rather than predatory intent and it has the potential to de-escalate an interstate conflict by overcoming two mindsets that can fuel security competition: peaceful/defensive self-images and ideological fundamentalism.

One way SDS is generated is through interpersonal face-to-face interaction. Wheeler (2018) argues that SDS is a key precondition for a process of social bonding which, in turn, he sees as a causal mechanism leading to the emergence of a specific type of trust between state leaders. Through a bonding process where two state leaders, in and through face-to-face interaction, come to both positively identify with the interests of the other and recognize the humanity in the other, self-other identities are transformed. He argues that if this process of identity transformation reaches a certain point - which he calls 'trust as suspension' - both leaders will suspend risk calculation in relation to the intent and integrity of the other leader $(2018,52)$. Suspension of risk calculation helps us to understand how leaders of states with previously enemy relations can put themselves in a position to trust one another and potentially transform a previously hostile interstate relationship. In the end, for Wheeler, social bonds are critical because they push leaders toward suspension of risk calculation.

These studies of interpersonal empathy and trust development shift the focus of analysis from the dispositions and traits of individuals to what occurs in the process of individuals interacting. This is not to suggest that traits or dispositions are unimportant. As alluded to above, an individual leader's ability to be empathic, levels of emotional intelligence, or ability to self-monitor, for example, have crucial implications for the social interactions in which they engage (Holmes 2018; Yarhi-Milo 2018). Yet, the wager placed in the study of the interpersonal is that outcomes are not merely additive; it is not enough to just have the right mix of dispositions and traits, but rather the interaction itself, how individual leaders engage when meeting face-to-face, is crucial to understanding both whether empathy or trust develops, as well as whether identities can change.

This domain of research has two major limitations. First, it has not identified what precisely creates a social bond and why they sometimes form and other times not. Holmes, for instance, argues that intention specificity is crucial when it comes to intention understanding engendered through face-to-face interaction: the more specific the intention, the more likely that it will be accurately read. Wheeler $(2018,16)$ argues that SDS is a 'necessary condition for the success of face-to-face interaction.' These minimal conditions are helpful for understanding what is required for face-to-face interaction to result in normatively positive outcomes, but provide an incomplete picture of why social bonds sometimes form and other times do not. 
Second, this literature has suffered from a positivity bias. Both Holmes and Wheeler, for example, focus on normatively desirable outcomes of intention-understanding and trust-building. Interpersonal interactions often go horribly wrong from a normative perspective. As the Kennedy and Khrushchev example above illustrates, two leaders might well understand the intentions of one another, and even perhaps appreciate the dimensions of the security dilemma in which they are both embroiled, and yet a negative social bond can form with deleterious consequences. The key question becomes not only why do positive bonds sometimes not form, but why do negative ones emerge?

\section{Emergence in dyadic relations: social bonds and interaction rituals A typology of interactions}

Micro-sociology has long been interested in how dyadic interpersonal relations create social bonds. Dramaturgical approaches in particular, beginning with Émile Durkheim's work (1912), continuing with Goffman (1959, 1956/1967), and most recently Turner $(2002)$ and Collins $(2004,2009)$, theorize both the nature of interpersonal interactions as well as the determinants of when such interactions are able to produce social bonds. The dramaturgical approach analogizes human interaction to the theater. Goffman views interaction as normally normatively scripted, with clear roles and expectations for how individuals within a particular interaction are supposed to behave, as if they were on stage performing in front of an audience. However, within that script, dramatic license is allowed and individuals behave strategically. Slip-ups can occur, allowing the audience insight into the 'backstage,' where 'the performer can relax; he can drop his front, forgo speaking in his lines, and step out of character,' (Goffman 1959, 112-13), but the bulk of interaction occurs in a strategic social setting where individuals typically know the script and more or less abide by it. Human interaction is therefore highly 'ritualized' in its predictability of form, structure, and even nuance.

The broad perspective the dramaturgical approaches share is that of symbolic interactionism (Berger and Luckmann 1966), brought into IR by Jervis (1989), Wendt (1999), and others, and implies that individuals are ultimately social and act on and upon social meanings. As Wendt puts it, '[p]eople act toward objects, including each other, on the basis of the meanings those objects have for them' (Wendt 1992, 396-97). Individuals engaged in an interpersonal interaction, such as a first encounter between Alter and Ego, are attempting to access and understand the meaning of the other while simultaneously managing the meaning they are expressing. And, as others have argued, symbolic interactionism occurs with individuals who are both meeting each other for the first time, such as those on a blind date, as well as individuals who are intimately familiar with each other, such as husbands and wives. 'Presentation of self captures the symbolic interactionism logic neatly: individuals consciously and unconsciously attempt to influence the perceptions others have in an interaction through their presentation, even in instances where individuals know each other quite well. The link between dramaturgy, symbolic interactionism, and international politics is that interactions at the international level are highly ritualized, scripted, and strategic ones where diplomats 
and leaders attempt to convey a particular meaning while simultaneously deriving the true meaning of the other.

In addition to interpersonal interactions allowing for a unique opportunity to assess and be assessed by others - with regard to levels of sincerity, honesty, deception, and so forth - they also have been shown to be particularly powerful in creating bonds between individuals. Durkheim, for instance, argued that repeated rituals, interactions he defined as those with relatively set structures and symbols, are key to the creation of social solidarity. ${ }^{10}$ Religious ceremonies are the example par excellence with sharp collective focus on supernatural forces, promoting positive social bond formation and group solidarity (Durkheim 1912/1915, 196). By participating in a religious ritual, individuals experience mutual coordination and '[feel] a rush of energy or collective effervescence' (McFarland, Jurafsky, and Rawlings 2013, 1599). Collective effervescence for Durkheim is characterized by individuals simultaneously experiencing, thinking, or feeling the same things and a group-feeling emerges at the collective level. This is both exciting to the individuals involved and helps to unify the group, often with long-lasting effects. For instance, even though the worshiping of the totem was momentary, the social bond remained after the ritual was over. Durkheim theorized that these types of processes were in play not only in religious rites, but also everyday interpersonal interactions. As he puts it, everyday 'positive neighboring relations' can result in a 'rush of energy.' Or as Shilling and Mellor $(1998,196)$ put it, the 'idea of social force at its birth.' The key point is that the output of these interactions is an emergent property. Having identified face-to-face interactions as important rituals of individual and collective social life, Durkheim and Goffman essentially put forth a dramaturgical approach to understanding social interaction. Yet why some interactions result in the 'rush of energy,' while others fail to, or why some interactions produce a momentary but fleeting rush of energy, and what precisely that entails remained underspecified.

Randall Collins' synthesis and extension of Durkheim and Goffman provides more specific propositions on when interaction rituals will be more likely to result in collective effervescence, and thus in turn, positive social bonding. ${ }^{11}$ For Collins, rituals are ubiquitous, existing 'almost everywhere' $(2004,15)$. They are interactions with others that can bring emotional payoffs and the promise of face-to-face interaction is straightforward: the power of these interactions is that when they succeed 'mutually focused emotion and attention [produce] a momentarily shared reality, which thereby generates solidarity and symbols of group membership' $(2004,7)$. A key assumption in Collins' work is that individuals seek this emotional payoff. Emotional energy, or 'EE,' is 'a feeling of confidence, elation, strength, enthusiasm, and initiative in taking action' (2004, 49). EE serves, as Bramsen puts it, as a

\footnotetext{
${ }^{10}$ In colloquial usage 'ritual' typically refers to a more restricted and formal event, such as a ceremony. Here we refer to ritual in the way understood by Goffman $(1956 / 1967,57)$ 'I use the term "ritual" because this activity, however informal and secular, represents a way in which the individual must guard and design the symbolic implications of his acts while in the immediate presence of an object that has a special value for him.' As Goffman elaborates, in everyday life rituals are ubiquitous and occur in stereotyped verbal interactions, such as 'good night' and 'goodbye' as well as formal substantive negotiations.

${ }^{11}$ There are few applications of Collins' micro-sociological approach to international politics, though see Bramsen and Poder (2014) and Bramsen (2017) for exemplars from which we draw.
} 
'[foundation] for agency' $(2017,2)$. Individuals experiencing EE are motivated to take the initiative and to act. When these types of interactions are repeated, what Collins terms 'chains of interaction,' durable, stable, and long-lasting EE can be created.

When is this payoff likely to occur? Collins $(2004,48)$ theorizes four broad conditions for the creation of positive emotional energy: bodily co-presence, mutual focus of attention, shared mood, and barriers to outsiders. ${ }^{12}$ Bodily co-presence is defined by Collins as 'two or more people physically assembled in the same place, so that they affect each other by their bodily presence, whether it is in the foreground of their conscious attention or not' $(2004,48)$. For Collins, $(2004,64)$ the key is that bodily co-presence allows individuals to 'monitor each other's signals and bodily expressions' such 'that human nervous systems become mutually attuned.' The mutual focus of attention refers to 'a common object or activity' where individuals in a dyad or larger group 'become mutually aware of each other's focus of attention' $(2004,48)$. Meandering conversations without a clear focus, or where there is a lack of attention paid to a common theme or question, will be less likely to result in positive experiences. However, in this face-to-face interaction individuals must also 'share common mood or emotional experience' (2004, 48). For Collins, the shared mood can result from what might be viewed as 'thick' empathy, the placing of oneself in the shoes of the other and understanding and appreciating where they are coming from in terms of interests, emotions, or other mental states. But it can also result from a 'thinner' version of empathy, the attunement that often derives naturally from face-to-face interaction: getting 'into shared rhythm, caught up in each other's motions and emotions' (2004, 64). Crucially for Collins, shared mood and mutual focus of attention may reinforce one another. As individuals become more mutually aware of the other's focus of attention, a common mood or affective experience may develop, in turn further heightening the focus on one another. Face-to-face facilitates this by allowing individuals 'to signal and confirm a common focus of attention and thus a state of intersubjectivity,' (2004, 64) creating an attunement between their physical bodies. Lastly, barriers to outsiders ensure 'that participants have a sense of who is taking part and who is excluded' $(2004,48)$ in the interaction itself.

When interaction rituals succeed, they produce a number of important shared experiences through the mechanism of collective effervescence discussed above that constitute the social bond. The bond is an emergent property of the interaction and is experienced by individuals in the interaction as 'hitting it off,' feeling 'personal chemistry,' and enjoying a 'sense of connection,' solidarity, and positive emotional energy (this process is depicted in Figure 1). Further, Collins suggests that group solidarity, even among minimal groups such as

\footnotetext{
${ }^{12}$ It is important to remember that Collins is attempting to create a general theory that will cover all forms of face-to-face interactions and thus his conditions are quite broad. Below we develop more specific conceptualizations of his conditions, relevant for international politics. Additionally, Collins leaves open the prospect that relationships can be built through non-face-to-face means, but he is skeptical that these interactions can generate similar amounts of emotional energy and solidarity that obtains through face-to-face interaction rituals (see van der Zeeuw, Keesman, and Weenink 2018, 248-49). We discuss this in more detail in the conclusion.
} 
Ritual Ingredients

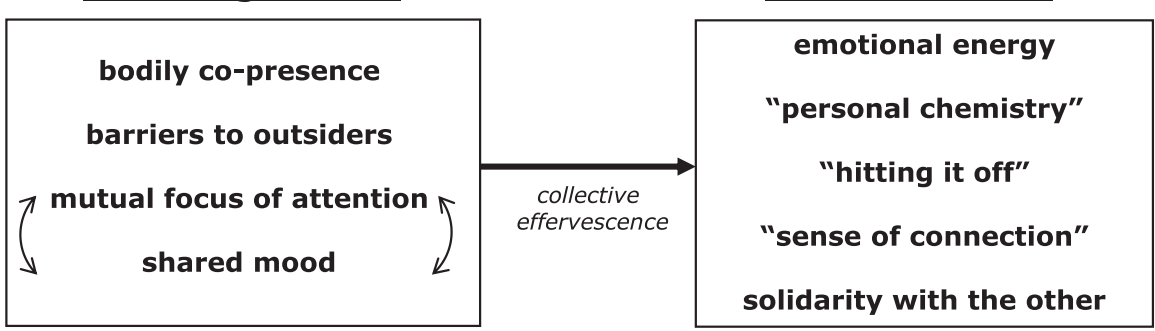

Figure 1. Interaction Ritual Process (adapted from Collins 2004).

dyads, allows participants in the interaction to have a feeling of membership and belonging with one another.

Finally, while the social bond is an emergent property that may be diffuse and difficult to directly pin down and measure, empirical manifestations of the bond, such as sense of connection or levels of emotional energy, are measurable.

Not all interactions produce positive social bonds for the parties involved. In contrast, some, perhaps most, interactions fall flat. As Collins argues, when interactions fail they can create in many ways the absence of positive EE: 'a sense of a drag, the feeling of boredom and constraint, even depression, interaction fatigue, a desire to escape' $(2004,51)$. For Collins, '[s] uccessful rituals are exhilarating; failed rituals are energy draining' $(2004,53)$. In these instances collective effervescence is not created and a positive social bond does not emerge. Collins also recognizes that some ritual outcomes might be even worse, creating negative emotional energy.

While Collins does not develop the concept fully, as his aim is to explain the positive 'hitting it off' characteristics of interaction rituals and theorize the ability to create in-group positive EE where it might not exist, Boyns and Luery $(2015,154)$ have introduced and theorized the concept of negative energy (ee -), which accounts for the possibility that negative social bond formation ensues. The intuition here, as Bramsen $(2017,2)$ argues, is that not all interactions are 'structured as solidarity-generating [and] cooperative.' Some interactions are characterized by their conflictual nature. Some might even be, as she puts it, 'domination rituals,' where one party seeks to control 'the rhythm of interaction and the other party follows submissively' (Bramsen 2017, 2). In these instances, either mutual focus of attention or shared mood is not present. For Boyns and Luery $(2015,154)$, '[h]igher levels of ee- can manifest as more highly-charged, "dramatic" emotions like embarrassment, resentment, anger, hatred, vengeance, rage, and fear; and result in the social experiences of conflict, aggression, distrust, cruelty, and revenge.' Again, here the negative bond is an emergent property and is akin to what some sociologists have termed 'emergent alienation': rather than solidarity with the other, estrangement characterizes the relationship, and is experienced locally as hostility and enmity rather than 'hitting it off.' Rather than a positive social bond being created, a negative one forms. 
In summary, these micro-sociological perspectives on dyadic face-to-face interactions ultimately suggest a typology of at least three interaction types, identified by their outcomes. These include 'hitting it off and creation of a positive social bond where the four ingredients to a successful ritual, with particular emphasis on mutual focus of attention and shared mood are present, on one end of the spectrum. The second category includes instances where there is a lack of collective effervescence and the interaction 'falls flat' due to a lack of mutual focus and shared mood. Finally, the third category encompasses experiences of negative emotions that are detrimental to the relationship and the formation of negative social bonds, the most drastic of which would be characterized by a bond of domination.

\section{From model to explanation}

In order to use this model to explain each of the outcomes predicted by Collins, the four ingredients need to be operationalized. Collins $(2004,15)$ notes that we can think about the ingredients to social interaction in terms of variables, with varying strengths: ' $[w] \mathrm{e} . .$. have a clear model of what social ingredients go into making a ritual, and what outcomes occur; and the strength of those ingredients are variables, which determines just how much solidarity occurs.' The upshot for Collins is that by thinking of the ingredients as variables, we can test what happens when the variables are present and their values varied. 'Rituals can fail, or they can succeed at different degrees of intensity. We can predict and test just what should result from these variable conditions' $(2004,15)$. The difficulty is that the content of the variables will differ from situation to situation. Mutual focus of attention may mean focusing on a carburetor in the sale of a used car in one instance and a stated intention to reduce nuclear armament in another.

One study, for example, applies the Collins model to a specific and particularly data-rich environment relatively far removed from diplomacy, though useful for demonstrating the potential utility of the interactionist model: speed dating. Speed dating provides a unique opportunity to observe face-to-face encounters that are highly scripted and ritualized, not unlike diplomacy from a symbolic interactionist or dramaturgical perspective. Speed dating is also useful in creating a predictive model that places emphasis on interaction because the individuals are typically unknown to each other, minimizing the impact of reputation and prior held beliefs about the other. In addition, the aim of the interaction is to find the 'personal chemistry' or 'social bond' that is critical to the ability to establish a relationship. Finally, in controlled settings a number of important variables, such as sex, gender, or personality characteristics/traits, can be measured and controlled. In short, researchers can demonstrate 'what qualities of interaction correspond with a sense of connection' (McFarland, Jurafsky, and Rawlings 2013, 1598), pinpointing what it is precisely about face-to-face interaction, if anything, that sometimes engenders the social bond - positive or negative - and other times does not. This is a critical test of the additive approach to interaction. If outcomes are determined by the existence of specific traits/dispositions, then we should be able to predict bonding outcomes based on personal characteristics exogenous to the interaction itself. 
McFarland, Jurafsky, and Rawlings (2013) investigate the determinants of bonding in 1100 4-minute dyadic speed dates. They ask three questions: (1) does the interaction itself matter at all to the creation of a social bond; (2) if so, what are the qualities of the interaction that matter for chemistry; and, (3) in what type of pattern do the interactions occur? They find that the Collins model holds up very well and that interaction matters for outcomes. In this particular heterosexual speed dating construct, 'placing men in a social position of seeking women and women in the position of selecting men' (1642), a sense of connection is made when individuals in the dyad 'assume complementary parts and keep the empowered part's self in focus.' Put simply, 'When the subordinate suitor (male in this case) reinforced this focus and aligned with the superordinate, and the empowered suitor (female) was engaged, they both regarded the encounter as a success and enjoyable. This occurred when men expressed sympathy and appreciation of their dates, and women targeted themselves as a subject ("I") and engaged the situation.' The mutual focus on the female was critical to success in building a positive bond. The dyads that were most successful in creating a bond tended to experience intensified emotions, but the mutual excitement felt within the dyad is expressed differentially among individuals. In general, for instance, men tended to laugh and vary their volume to convey emotional intensity while women raised and varied their pitch. This is not to say that individual characteristics do not matter; traits, such as height, where one was born, and so on clearly mattered and explain a significant amount of the variation, but so did the subtle interactional communicative actions that 'correspond with a sense of dyadic effervescence' (1640).

As the authors note, speed dating is clearly structured in somewhat of a unique way. We present it here not to suggest that diplomacy is akin to speed-dating (though there may be some parallels), but rather to demonstrate how an interaction model can be used to predict bonding outcomes in a data-rich environment where dispositional/trait factors alone cannot explain outcomes. Other similar studies have applied the Collins theory in more conventional settings, including explanations of entrepreneurial behavior in business (Goss 2007; Doern and Goss 2014), large-scale organizational dynamics (Stephens, Heaphy, and Dutton 2011), large music festivals using geospatial analysis and surveys to map and test for emotional energy (Liebst 2019), harp singing (Heider and Warner 2010), restorative justice conferences (Rossner 2011), and the pedagogical advantages of rituals through face-to-face interactions with students in the classroom (Allais 2014). Crucially, however, unlike speed-dating, these studies tend to focus on group behavior, rather than dyadic interaction. Further, we have yet to see a direct application to diplomacy or IR writ large.

\section{Social bonding in diplomacy: an explanatory model}

The preceding analysis suggests a simple testable proposition: if the four aforementioned ingredients are present in an interaction, then a positive social bond will result. If not, we would expect a flat interaction or a negative one. At worst, where negative energy is present, such as through domination, the interaction will leave at least one of the individual(s) involved with a negative experience and a shared negative social bond will form. In order to operationalize and test 
these ingredients for the study diplomacy, however, a similar exercise to that conducted with speed dating is needed.

Bodily co-presence is constituted by face-to-face interaction in a shared physical environment. For Durkheim, Goffman, and Collins, the spatial proximity and shared space is an important factor in individuals' ability to understand and respond to one another. As Goffman puts it, 'persons must sense that they are close enough to be perceived in whatever they are doing, including their experiencing of others, and close enough to be perceived in this sensing of being perceived' (Goffman 1963/2008, 17). Collins is skeptical that modern technologies, such as video-conferencing and email can produce the same emotional energy and hence positive social bond formation as bodily co-presence (2004, 54-56), suggesting that interaction through other modalities, be it a cable wire, telephone call, Tweet, or perhaps even video conferencing may not be sufficient (though see DiMaggio et al. 2018). Collins notes, however, that this may be largely an empirical matter; we take this question up further below.

While Collins does not specifically elaborate on why physical human bodies themselves are critical ingredients, except to implicate them in perception and response to the expressive behaviors of others, there are several literatures in social theory (see Shilling 2003), applied linguistics (see Streeck, Goodwin, and Lebaron 2011), anthropology (Turner 2002), neuroscience (Heinskou and Liebst 2016), and feminist relational theorizing (see Pedwell 2014) among others, that are instructive in that they appreciate the importance of the body for different reasons, but all share the importance of bodily co-presence with respect to meaningful and purposeful social interaction. ${ }^{13}$ Feminist relational theorizing, for example, has theorized the importance of body relations for development of 'empathic responsiveness in the context of interpersonal mutuality' (Jordan 1986, 2). Here, and resonating with Collins on the positive bonding side, the 'affective attunement to the other' and 'ability and willingness to feel the presence of each other, and the impact each has made on the other' is required to develop 'mutual relational flow or movement between people' (Freedberg 2007, 254). As Pedwell $(2014,184)$ cautions, however, whatever relations are cultivated by bodies, such as what she terms 'affective relations,' are 'produced and circulated in and through transnational relations of power,' including 'complex intersections of empire, slavery, colonialism, diaspora, migration, development, globalization, neoliberalism, global media, and international security paradigms.' Bodily co-presence in politics always takes place within a context of power, in other words. And, relatedly, the feminist perspective also elucidates some important aspects of 'domination rituals,' which we discuss in more detail below.

Barriers to outsiders imply that individuals engaged in a diplomatic encounter have a method for isolating themselves from those not engaged in the interaction. This need not necessarily require that others are not in the same physical space, but rather it is clear who is taking part and who is not taking part in the interaction. For example, diplomatic encounters will often involve individuals who share the same physical space, but are nonetheless excluded by the individuals who are part of the ritual. In the same room with Gorbachev and Reagan were translators, note-takers,

\footnotetext{
${ }^{13} \mathrm{We}$ thank one of the anonymous reviewers for highlighting this literature.
} 
advisors, and photographers. While each of these individuals occupied the same physical space, Reagan and Gorbachev were able to exclude them from the interaction ritual itself. Sometimes this exclusion is more overt, such as the 30 minutes North Korean leader King Jung-un and South Korean President Moon Jae-in spent alone sitting on a park bench in Panmunjeom, North Korea at the May 2018 Inter-Korean Summit. In either case, the ability to exclude, either subtly or overtly, who is involved in the interaction is critical. Finally, as we will elaborate below, the inability to exclude outsiders is another reason why digital technologies may not (yet) be able to fully replicate the four ritual ingredients, as video-conferencing, provides essentially a two-dimensional representation of a three-dimensional space, without the ability to see all aspects of that space. Leaders interacting via video-conferencing are not able to see who may be behind or 'off camera,' creating an inability to guarantee that outsiders are barred from the interaction.

The final two components of a successful interaction, mutual focus of attention and shared mood, are necessarily context dependent. In diplomacy, for mutual focus of attention we highlight the importance of shared SDS, which as noted earlier is an intuition that an adversary is acting out of fear and not malign intent. For Booth and Wheeler $(2008,7)$, SDS might well be asynchronous, in that one actor might exercise it, but the other does not. For example, a leader might have a strong desire to end a conflict and understand that their own actions have facilitated the growth of the conflict. In order for a positive bond to form, however, this SDS intention and capacity needs to be shared by his or her counterpart, and, crucially, both sides need to know that the other shares it. If one side exercises SDS and the other does not, there is not a mutual focus of attention that both sides are responsible for the conflict and that each side realizes they are jointly trapped in this conflict together. It may be that through face-to-face diplomacy each side is able to jointly and simultaneously arrive at SDS and thereby satisfy the condition that it be the mutual focus of both parties. But prior to that moment we would not expect this key Collins condition to be satisfied. This further highlights the importance of bodily co-presence and individuals responding to the bodily signals that are provided in face-to-face interaction. As Wheeler (2018) argues, it is possible that individual leaders possess a SDS intuition, yet until that interpersonal interaction occurs, neither side knows that the attitude is mutually shared. Collins argues that mutual focus of attention and shared mood are mutually reinforcing, a position we agree with, but in our model, it is the mutual focus of SDS that has to be achieved before the fourth variable of shared mood in Collins' model can develop.

Shared mood ${ }^{14}$ comprises two distinct components: positive identification of interests and humanization. Positive identification of interests is drawn from Wheeler's $(2018,61)$ analysis of trust-building in face-to-face interactions. It refers to a process by which 'state leaders no longer [think] of their interests being autonomous, even if congruent... they need to see the other's interests as their

\footnotetext{
${ }^{14}$ There is a relative dearth of research on the role of moods, particularly shared moods, in political science, though see Ringmar (2018) on the development of 'public moods.' Ringmar too highlights the importance of human bodies becoming in 'close physical proximity' to one another, and the emotional, cognitive, and physical attunement that may follow.
} 
interests, and the other's security and well-being as their security and well-being.' This occurs when the individuals involved in an interaction share the other's security concerns. Importantly, however, this does not necessarily imply that the positions held by both individuals will be congruent. Two leaders may come to identify with the interests of one another and disagree on how to achieve those interests. Through archival work it appears clear that both Reagan and Gorbachev truly intended a peaceful end to the Cold War; they disagreed vehemently, however, over the steps to get there, with Reagan preferring a technological solution (Strategic Defense Initiative), while Gorbachev opposed, at least initially, the entire concept.

The second component of shared mood is humanization of the other. Wheeler notes the importance of 'see[ing] the "human" in their counterpart's attitudes and behaviour rather than just a representative of cold state interests' $(2018,62)$. Humanization may involve several processes that are facilitated by face-to-face interaction. At a material level, psychologists highlight 'chameleon effects' which are present when people automatically adjust their own expressive behaviors to that of the other, mimicking facial expressions, bodily positions, and so forth, signaling to each that the other is not all that unlike the self (Chartrand and Bargh 1999, 893-910). More cognitively, empathy is implicated here, as it is the process by which individual leaders conceive of the other as someone like themselves, with emotion, agency, and so on. Humanization is shared because it orients both sides to seeing the humanity in the other. As we noted earlier, Gorbachev himself coined the term 'human factor' to capture how personalized diplomacy can break down barriers to cooperation that exist at the inter-state level as two leaders meet each other as human beings.

For Collins, collective effervescence is the mechanism by which these four ingredients result in a positive social bond. Collective effervescence refers to contemporaneous and simultaneous thought, action, or communication. For Durkheim (1912/ 1915, 162), collective effervescence 'generates a kind of electricity that quickly transports them to an extraordinary degree of exaltation.' The form collective effervescence takes may vary by interaction, however. Sometimes the synchronicity is overt. At the first of the aforementioned summits between Reagan and Gorbachev, in Geneva in 1985, both leaders recount a moment in time where synchronicity occurred. '[T]hey locked hands and eyes with a sudden affect that had in it elements of relief (Morris 2000, 568). Gorbachev recalled a 'spark of electric mutual trust which ignited between us, like a voltaic arc between two electric poles' (Hunt and Reynolds 2016, 160), while Reagan recounts that 'after almost five years I'd finally met a Soviet leader I could talk to' (Reagan 1990, 641). In other cases, the collective effervescence may be observationally more subtle, with displays of collective emotions through mimicry (see Hess, Houde, and Fischer 2014). In either case, what is shared between the subtle and overt versions is the excited reaction of experiencing something together.

On the negative end, in interaction marked by domination, the electricity experienced together is not pleasant in nature. It is mechanistically similar to collective effervescence in its causal power, but the emergent bond is experienced locally by the individuals involved as 'negative emotions like hatred, resentment, and vengeance,' alienation with the other, and the 'contravention of trust' and 
solidarity (Boyns and Luery 2015). Positive identification of interests and humanization of the other either are not present and one or both of the actors fail to see the other as an agent operating outside the confines of cold state interests. SDS is similarly not present and may instead be replaced with a zero-sum conception of security. Crucially, whereas a positive social bond may result in suspension of risk-calculation, negative bonds push leaders toward specific behaviors: ideological fundamentalism, a 'syndrome... that because of what the other is,' behavior is viewed as both untrustworthy and threatening (Booth and Wheeler 2008, 65).

In place of mutual focus of attention and shared mood, face-to-face interactions that fall flat or engender strong negative emotional energy, often exhibit characteristics of either projection or rational perspective-taking. We refer to projection as the process by which individuals understand each other by projecting onto the other their own beliefs, values, and fears, leading to them assuming that if they were in the other's position, they would act in particular ways that are understandable in terms of these predispositions. However, such projections may not accurately understand and experience the cognitive and affective mental states of others. A good example of this kind of projection is the belief on the part of many Western strategists that Iran must be seeking to develop a nuclear weapon because it is surrounded by hostile foes; the projection is that if those strategists were advising the Iranian Government, they would likely be advocating the development of nuclear weapons. Rational perspective-taking, in contrast, is the attempt to understand where the other is coming from by focusing on the other rather than the self, but it still suffers from the problem that the actors exercising this form of empathy for the security concerns of the other do not know that the other understands this, or feels the same unless this realization develops in face-to-face interaction. Finally, bodily co-presence may exacerbate domination when emotional attunement is not obtained or bodily expressive behavior is used to distance oneself from the other or to symbolically dominate the other. Several scholars and observers have noted the extent to which President Trump, for example, engages in bodily domination, much of which is often highly gendered and/or norm-violating (see, e.g., Collins 2018; Grebelsky-Lichtman and Katz 2019), and results, in our analysis, in an interaction that falls flat.

Empirically, dyadic interactions come in all shapes and sizes in world politics. Highly successful relationship-transforming interaction rituals where all four ingredients are present, arguably such as the Gorbachev-Reagan summitry, may be relatively rare under anarchy where leaders fear dissembling and defection, and thus have difficulty achieving mutual SDS, positive identification of interests, and humanization. Interactions where some, but not all, of the ingredients are present are more likely. The Obama-Putin interactions arguably exhibited an inability, or lack of desire, to create mutual SDS, with each side maintaining a view that their interests were inherently at odds, could not be harmonized, but most importantly could not both agree that the source of the problem included themselves. In other cases, SDS and shared mood may give way to domination, with one side attempting to control the interaction, as some analysts have interpreted the 1961 Vienna summit between Khrushchev and Kennedy (Meerts and Vukovic 2015, 92). 


\section{Problematizing parsimony}

We have argued for a relatively parsimonious approach to understanding social bonding in diplomacy. By way of conclusion, we will discuss some of the complicating factors that affect the model, identify limitations of the theory, and point toward the development of a research agenda focused on the determinants of social bonds in international politics. In what follows we first discuss endogeneity issues, the related problem of divergent interests, how to deal with other factors that exist outside of the Collins model, but nevertheless are clearly relevant, such as leader traits and dispositions, and what the digital revolution, particularly videoconferencing, might mean for the future of social bonding in diplomacy.

With respect to endogeneity, there are two main concerns. First, it may be that factors outside of the interaction determine whether leaders meet at all, biasing any interaction toward a positive outcome. Consider the 'dogs that do not bark' problem. The balance of power, distribution of ideas, timing of a crisis, and so forth, may all affect whether two leaders are able to meet. For example, some of the most salient face-to-face encounters at the end of the Cold War, such as George H.W. Bush and Mikhail Gorbachev's meeting in Malta in December 1989 to discuss the fallen Berlin Wall and plan for Germany, were made possible by significant power shocks to the international system. The physical teardown of the wall created an imperative to resolve the situation. At other times, power dynamics have constrained the opportunity for a process of face-to-face interactions to develop. One of the arguments proffered by analysts regarding the lack of interactions between leaders of the United States and Russia has to do with the lack of an impending structural imperative to meet (Dunn and Wheeler 2015). Unlike in the Cold War period, the two powers do not seem to perceive the same level of existential crisis, removing a potential key enabling condition for face-to-face interactions, and thus the bonding that may result, from occurring. Ironically, it may be that the geopolitical situation is not perceived as severe enough to enable bonding. If leaders are more likely to meet when the situation is 'ripe' for an agreement, one might argue that we would expect more positive outcomes and less domination outcomes, biasing our model to the positive end of the bonding spectrum.

Relatedly, if face-to-face interactions require a host of conditions to be met, it may be that one could argue that a connection, or bond, of some form has already obtained in these instances, suggesting that bonding precedes, rather than follows from, the interpersonal interactions themselves. Or, perhaps conditions for bonding flow from the bonds themselves. When Kim Jung-un and Moon Jae-in walked off alone with one another was this a bonding ingredient or an indication that they had already bonded? It is important to remember that for Collins, positive bonds are ones which are experienced as emotional energy, excitement, solidarity with the other, confidence, or even elation in individuals. Leaders and diplomats can interact and communicate with one another, and even get along, without producing a strong social bond. And sometimes the presence of one or more ritual ingredients will be present as they do so. As Wheeler $(2018,143-91)$ points out, for example, the Reagan and Gorbachev interactions did not result in a strong bond right off the bat; mutual focus of attention and shared mood took time to develop. Empirically, this points to the need for careful qualitative process tracing of face-to-face 
interactions in diplomacy, ideally with declassified records and transcripts of the interactions themselves. Similarly, this is where larger quantitative studies of interactions, either observational as in the speed dating example or in-the-field experiments conducted as in the music festival example, may supplement process tracing and help researchers to better isolate the direction of the causal arrow.

As is the case with many other examinations of high-level diplomacy, the theory we propose here necessarily interacts with, and is affected by, other levels of analysis and takes place within particular power and historical structures. Leaders who wish to engage with their counterparts might face the challenge of making any agreement stick with domestic constituencies, veto players, and policy makers who might have other interests; and relatedly, the uncertainty of how far they can rely on the other leader to carry through their promises and agreements. In addition, leaders face the challenge of how to ensure that agreements negotiated by them will not be repudiated by their successors, with a detrimental impact on the security of the states concerned. Shifrinson (2016), for instance, has recently pointed to NATO enlargement as an example of why leaders should be wary of agreements crafted in interpersonal face-to-face interaction. Whereas Gorbachev believed that his interactions with George H.W. Bush and Secretary of State James Baker concluded with a promise not to enlarge NATO into Eastern Europe, future U.S. policymakers either did not have that understanding or decided not to honor it. This misperception or deception would have significant consequences for current USRussian relations.

This raises the question as to what extent substantive disagreements, interest conflicts, and diverging goals prevent the formation of positive bonds or facilitate negative ones. This is important in two ways. First, as discussed above, divergent interests may mean that face-to-face interactions never occur. Additionally, however, it may be that within an interaction individuals gain information that make positive identification of interests or shared SDS difficult. Putin gave expression to this obstacle to cooperation when he said after meeting Obama in September 2013: 'We hear each other and understand the arguments. But we simply don't agree. I don't agree with his arguments and he doesn't agree with mine, but we hear and try to analyze' (Karpukhin 2013). This suggests that divergence of interest may be one of the key stumbling blocks to bond formation. One is similarly reminded of Charles V's (attributed) famous quip when asked about his dispute with his cousin, Francis I, regarding the Duchy of Milan. The Holy Roman Emperor is reported to have said that, 'My cousin Francis and I are in perfect accord - he wants Milan, and so do I.' We have suggested however, that positive identification, humanization, and SDS can all develop through interaction. Reagan and Gorbachev disagreed with one another's arguments as well in 1985 but were able to see past the positions of one another to core interests of security over the course of iterative meetings.

Yet, the presence of interest or preference division in world politics suggests a key question that remains unresolved: can the leaders of states with divergent 'type,' that is goals that are completely antithetical to the other, create a social bond? A revisionist power, to use realism's language, may full well understand the deleterious aspects of the security dilemma, but nevertheless remain unassurable because they do not seek to be assured or do not believe they are in a dilemma 
situation at all. Or in some cases an aggressive state may use empathy, or its counterpart's, in order to make the other weaker. After all, one may recognize that one has made the other insecure, but also believe that this is the best path forward for one's security because you think that the other has prisoner dilemma (PD) preferences or because you are $\mathrm{PD}$ and you think they are assurance game (AG) players. In other cases it may be virtually impossible for leaders to successfully reassure the other. Debates regarding North Korea's nuclear program, for example, tend to revolve around the extent to which either or both actors are aggressive actors or AG players and the extent to which both sides can successfully signal this to the other. Developing a social bond if both are not looking to reassure and be reassured may be difficult, or perhaps in some cases, impossible.

With respect to the Collins model presented here, it perhaps goes without saying that the structure of diplomatic interaction is in many ways different from other types of interaction, such as speed-dating. While we have suggested similarities in the enterprises, namely the emphasis on interaction over dispositions or other characteristics, important differences remain. Unlike speed dating, international diplomacy takes place in a thick political context, where history, culture, and the moves made prior to the interaction all affect the interaction itself, as Collins points out. Speed dating is more akin to Alter and Ego interacting as relatively blank slates in a first encounter (Wendt 1999) (though each presumably has some sense of what one wants in a partner); international diplomacy is more iterative, even if the leaders themselves have not met. Gorbachev in the 1980s was aware of Reagan, well versed in American politics and culture, and thus had 'interacted' with the United States before. Additionally, while diplomacy and speed-dating surely both involve the following of scripts, in the Goffman sense, to a large degree, the scripts are different and the details of the scripts left unwritten, allowing considerable agency for the leaders. Most importantly, however, as in the speed-dating empirical discussion, traits of leaders likely matter a good deal. These may be different from those relevant for romantic dating, but it is almost certainly the case that dispositional traits or other characteristics of the individuals account for a significant amount of the variation in bond formation. This likely occurs in two ways. First, dispositions may affect how likely it is that particular leaders will pursue face-to-face interactions with one another. Second, once in the interaction itself, dispositions may make it more or less likely that the ingredients, such as SDS obtain. As Booth and Wheeler argue, SDS is a capacity as well as a mental state. The capacity to understand the dynamics of the security dilemma may well be dependent on an ability to empathize with, or take the perspective of, the other side.

Narcissism is one such dispositional trait that is heavily implicated in empathy or lack thereof. Psychologists have long suspected that narcissism is negatively correlated with empathic capacity. Individuals who have narcissistic personality disorder (NPD), for example, have tended to display a 'lack of empathy' in clinical investigations (Kohut 1966). Recently, however, researchers have been able to identify variation in how individuals with NPD utilize different forms of empathy: cognitive and affective. Cognitive empathy refers to the ability to 'take another person's perspective and to represent others' mental states' (Ritter et al. 2011), whereas affective empathy refers to the ability to feel what another person is feeling in terms of their emotional states. Individuals with NPD struggle to exercise affective 
empathy but not cognitive empathy. Put into the context of interpersonal interaction and diplomacy, this may suggest that individuals with narcissistic personalities are more likely to engage in perspective-taking and projection, but crucially, less likely to develop mutual focus of attention and shared mood that require not seeing the other as a manifestation of the self, but feeling their interests and concerns.

Self-monitoring, on the other hand, may be productive for positive social bonding. Self-monitoring refers to one's ability to be aware of, and respond to, one's own behavior and the behavior of others, in social situations. Individuals who are high self-monitors typically care a great deal about the impressions they give off in face-to-face interactions, for example, and how those impressions are received by the other party. Low self-monitors are concerned more with their inner beliefs or desires and less on the exogenous conditions of their surroundings, including those around them. Keren Yarhi-Milo's (2018) intricate analysis of self-monitoring in leaders suggests wide variability among U.S. Presidents, for example, but the upshot is that high self-monitors, even dovish ones, exhibit a strong regard for their reputations for resolve and more generally the external audience that is evaluating them. For our purposes, self-monitoring has also been linked to interpersonal relationship development (Ickes et al. 2006). Because high self-monitors are often very attuned to the Other, and assessing the Other's behavioral reactions in response to the Self, and attempt to elicit positive affect and emotional response from others, it is likely that the development of mutual focus of attention and shared mood, for example, will be enhanced when the interaction involves high self-monitors.

While existing research suggests that trait-based prediction of bonding is quite difficult, and indeed one reason why sociologists have turned to interaction itself, a growing body of research combines the types of dispositions discussed above with interactional elements. Intelligent virtual agent research is informative. The aim is to create autonomous virtual agents that resemble human agents as much as possible. Jaques, Kim, and Picard (2016), for example, show how by analyzing human interactions it is possible to account for both traits such as personality, as well as the interaction elements, both in terms of what is said as well as what is expressed through facial expressions and mannerisms (see also Jaques et al. 2016). New technologies and methods facilitate this type of analysis. For example, Alex Pentland (2008) and colleagues have devised sociometers, essentially wearable devices that capture data that can be used to create computational models of face-to-face interactions. In terms of the Collins model, sociometers can be used to measure talkativeness, arousal evidenced in speech patterns, voice timbre changes, and so on, in order to provide a quantitative measurement of attunement, entrainment and, potentially, behavioral indicators or proxies of collective effervescence. While it remains to be seen whether this type of analysis will eventually lead to a full-fledged model of interaction that can account for dispositions/traits as well as the interaction elements itself, the sociometer approach of using automated analysis to provide a computational model of interactions provides significant excitement, promise, and new research avenues to the study of face-to-face interactions.

More generally, and of crucial importance for future research, are theoretical and empirical questions regarding the extent to which the argument generalizes and the 
extent to which social bonds may form outside of face-to-face interaction. Our focus here has been on high-level summitry in reassurance contexts, as this is the location where most existing research has looked at the importance of face-to-face interactions, but face-to-face meetings occur between and within governments at various levels, from negotiations within international organizations to lower-level diplomatic encounters. It also routinely occurs between allies who are not necessarily attempting to reassure one another, but rather maintain or strengthen an existing trusting relationship. The basic Collins model should, theoretically, apply in each of these domains, though the specific operationalization of the four ingredient variables may well differ; whereas SDS is crucial for reassurance in relations of enmity, it may be less relevant for World Trade Organization (WTO) interactions or peacetime summits and conferences. Finally, as Collins admits, relationships do often get started, or can be strengthened, through non-face-to-face modalities, though he expects the emotional payoff of the bond to not obtain unless dyadic engagement through face-to-face occurs. This leaves open the possibility, to be explored empirically, the extent to which exchange of letters, such as those between Kennedy and Khrushchev during the Cuban Missile Crisis in 1962, as an example, were able to mitigate the deleterious domination experienced in Vienna a year earlier.

Finally, one of the implications of the digital revolution is that leaders and diplomats have the ability, if they choose, to communicate virtually instantaneously through email or social media, or even meet 'face-to-face' in a virtual way, through video conferencing technology. A burgeoning literature in 'digital diplomacy' has argued that social media allows diplomats, policymakers, and increasingly leaders, to maintain and sustain relationships remotely (Bjola and Holmes 2015). There is also evidence to suggest that at least among lower-level policymakers, individuals are increasingly making use of video conferencing technologies (Parajon 2019). Recalling the Collins ingredients, physical co-presence requires the sharing of the same physical space. Can cyberspace substitute for physical space? Collins himself remains skeptical that digital technology offers the same ability to bond that bodily co-presence does. With respect to non-video electronic communication, Collins argues that they often 'lack the flow of interaction in real time; even if electronic communications happen within minutes, this is not the rhythm of immediate vocal participation... There is little or no buildup of focus of attention in reading an email, or paralinguistic background signals of mutual engrossment...the more that human social activities are carried out by distance media, at low levels of [interaction ritual] intensity, the less solidarity people will feel...' (Collins 2004, 63-64). One might think that video conferencing overcomes these limitations, yet as Collins notes, '[p]eople in important economic and political positions almost always meet face-to-face for important business. Their success depends on being able to exert emotional influence over somebody and to pick up clues of what they are dealing with' (van der Zeeuw, Keesman, and Weenink 2018).

One reason for this may be the perception by users of video conferencing that it is 'cold, impersonal, unsociable, and insensitive' (Hauber et al. 2005, 1). Individuals interacting face-to-face often report a higher 'interaction quality' relative to its digital equivalent (Andres 2002, 39). There are several hypothesized reasons for this. First, media richness theory suggests that video conferencing, while clearly more information rich than many other modalities such as telephone or text 
message, lacks much of the sensory experience provided in face-to-face interactions. Not only is video-conferencing typically 'head-to-head' rather than 'body-to-body,' reducing the sensory input of expressive bodily behaviors that represents a significant amount of non-verbal communication (Nguyen and Canny 2009), but the medium, even at high resolutions, is not data-rich enough to allow individuals to pick up on subtle facial expressions, micro-expressions, and other expressive clues that may reveal mental states. Finally, as noted above, the inability to ensure outsiders are barred from a video interaction (individuals may be 'off screen' but still present) likely limits the usefulness of the technology for bonding purposes.

Digital technology may, however, provide an important variable that makes meeting face-to-face more likely. Richard Ling (2010) argues that with ubiquitous mobile phones, individuals are able to begin and cultivate relationships with one another, but then often want to bring their interactions face-to-face. Collins suggests that leaders may be similar. 'The powerful people would be the ones who could use the media to just the extent that they need them, but also meet face-to-face to create alliances and gain dominance' (quoted in van der Zeeuw, Keesman, and Weenink 2018). Put into political terms, emails, phone calls, even Tweets, may be useful in bringing leaders to the summit, but to build enough positive emotional energy to create a beneficial social bond, or negative energy to dominate, requires interacting face-to-face.

Acknowledgments. This paper immensely benefitted from a number of presentations and excellent feedback from discussants, panelists, and colleagues. Presentations included McGill University in March 2016, the International Studies Association Conference in Atlanta, Georgia in March 2016, University of Virginia in September 2017, the British International Studies Association Conference in Edinburgh in September 2017, University of Birmingham in December 2018, St. Andrews University in January 2019, London School of Economics in February 2019, and University of Oxford in February 2019. In addition to attendees and panelists at these presentations, we would in particular like to thank Corneliu Bjola, Chiara Cervasio, Emily Jackson, Joshua Kertzer, Anthony Lang, Adrian Rogstad, Eric Parajon, Vincent Pouliot, Andrew Ross, Peter Wilson, George Yin, Mike Tierney, Ana Alecsandru, and Sue Peterson, who all provided detailed comments and feedback on the paper. We would also like to thank the Global Research Institute at William \& Mary for generous research support.

\section{References}

Adler, Emanuel, and Vincent Pouliot. 2011. “International Practices.” International Theory 3(1):1-36.

Allais, Stephanie. 2014. "A Critical Perspective on Large Class Teaching: The Political Economy of Massification and the Sociology of Knowledge." Higher Education 67(6):721-34.

Andres, Hayward. 2002. "A Comparison of Face-to-Face and Virtual Software Development Teams.” Team Performance Management 8(1/2):39-48.

Berger, Peter L., and Thomas Luckmann. 1966. The Social Construction of Reality. New York: Anchor Books. Berridge, G. R. 1995. Diplomacy: Theory and Practice. London: Prentice-Hall.

Bially-Mattern, Janice. 2011. “A Practice Theory of Emotion for International Relations.” In International Practices, edited by Emanuel Adler and Vincent Pouliot, 63-86. Cambridge, UK: Cambridge University Press.

Bjola, Corneliu. 2013. "Understanding Enmity and Friendship in World Politics: The Case for a Diplomatic Approach." The Hague Journal of Diplomacy 8(1):1-20.

Bjola, Corneliu, and Marcus Holmes. 2015. Digital Diplomacy: Theory and Practice. New York, NY: Routledge.

Bleiker, Roland, and Emma Hutchison. 2008. "Fear No More: Emotions and World Politics." Review of International Studies 34(S1):115-35. 
Booth, Ken, and Nicholas J. Wheeler. 2008. The Security Dilemma: Fear, Cooperation, and Trust in World Politics. Basingstoke, England: Palgrave Macmillan.

Boyns, David, and Sarah Luery. 2015. "Negative Emotional Energy: A Theory of the 'Dark-Side' of Interaction Ritual Chains." Social Sciences 4(1):148-70.

Bramsen, Isabel. 2017. "How Violence Breeds Violence: Micro-Dynamics and Reciprocity of Violent Interaction in the Arab Uprisings." International Journal of Conflict and Violence 11:1-11.

Bramsen, Isabel, and Poul Poder. 2014. "Theorizing Three Basic Emotional Dynamics of Conflicts: A Situational Research Agenda." Peace Research: The Canadian Journal of Peace and Conflict Studies 46(2):51-86.

Breslauer, George W., and Richard Ned Lebow. 2004. "Leadership and the End of the Cold War: A Counterfactual Thought Experiment." In Ending the Cold War: Interpretations, Causation, and the Study of International Relations, edited by Richard K. Herrmann and Richard Ned Lebow, 161-188. New York, NY: Palgrave Macmillan.

Byman, Daniel L., and Kenneth M. Pollack. 2001. "Let Us Now Praise Great Men: Bringing the Statesman Back In." International Security 25(4):107-46.

Chartrand, Tanya L., and John A. Bargh. 1999. "The Chameleon Effect: The Perception-Behavior Link and Social Interaction." Journal of Personality and Social Psychology 76(6):893-910.

Collins, Randall. 2004. Interaction Ritual Chains. Princeton, NJ: Princeton University Press.

Collins, Randall. 2009. Violence: A Micro-Sociological Theory. Princeton, NJ: Princeton University Press.

Collins, Randall. 2018. "Kim Jong Un's Subdued Face with Trump: What effect did meeting Trump have on Kim Jong Un?” The Sociological Eye, 3 July. https://www.drrandallcollins.com/sociological-eye/2018/7/3/ kim-jong-uns-subdued-face-with-trump-what-effect-did-meeting-trump-have-on-kim-jong-un.

Copeland, Dale C. 2000. "Review: The Constructivist Challenge to Structural Realism: A Review Essay." International Security 25(2):187-212.

Crawford, Neta C. 2014. "Institutionalizing Passion in World Politics: Fear and Empathy." International Theory 6(3):535-57.

Damasio, Antonio R. 2000. The Feeling of What Happens: Body and Emotion in the Making of Consciousness. Mariner Books.

Derian, James Der. 1987. "Mediating Estrangement: A Theory for Diplomacy." Review of International Studies 13(2):91-110.

DiMaggio, Paul, Clark Bernier, Charles Heckscher, and David Mimno. 2018. "Interaction Ritual Threads: Does IRC Theory Apply Online?" In Ritual, Emotion, Violence: Studies on the Micro-Sociology of Randall Collins, edited by Elliott B. Weininger, Annette Lareau, and Omar Lizardo. New York, NY: Routledge.

Doern, Rachel, and David Goss. (2014) "The Role of Negative Emotions in the Social Processes of Entrepreneurship: Power Rituals and Shame-Related Appeasement Behaviors." Entrepreneurship: Theory and Practice 38(4):863-90.

Dunn, David Hastings, and Nicholas J. Wheeler. 2015. "The Geneva Summit Thawed the Cold War - So Why Have We Squandered Its Legacy?" The Conversation, 19 November. http://theconversation.com/ the-geneva-summit-thawed-the-cold-war-so-why-have-we-squandered-its-legacy-50628.

Durkheim, Émile. 1912/1915. The Elementary Forms of the Religious Life. London, UK: George Allen \& Unwin Ltd.

Freedberg, Sharon. 2007. "Re-examining Empathy: A Relational-Feminist Point of View." Social Work 52(3):251-59.

Goffman, Erving. 1959. The Presentation of Self in Everyday Life. New York: Anchor Books.

Goffman, Erving. 1963/2008. Behavior in Public Places: Notes on the Social Organization of Gatherings. New York, NY: The Free Press.

Goffman, Erving. 1967. Interaction Ritual: Essays on Face-to-Face Behavior. Chicago: Aldine Publishing Company.

Goss, David. 2007. “Enterprise Ritual: A Theory of Entrepreneurial Emotion and Exchange.” British Journal of Management 19(2):120-37.

Grebelsky-Lichtman, Tsfira, and Roy Katz. 2019. "When a Man Debates a Woman: Trump vs. Clinton in the First Mixed Gender Presidential Debates." Journal of Gender Studies, 1-21.

Hall, Todd. 2017. "On Provocation: Outrage, International Relations, and the Franco-Prussian War." Security Studies 26(1):1-29. 
Hall, Todd, and Andrew Ross. 2015. "Affective Politics after 9/11." International Organization 69(4):847-79.

Hauber, Jörg, Holger Regenbrecht, Aimèe Hills, Andy Cockburn, and Mark Billinghurst. 2005. "Social presence in two- and three-dimensional videoconferencing." Presence. https://pdfs.semanticscholar.org/ e221/0b709b8eeb049f60a8181e9ff94e96ed1770.pdf

Head, Naomi. 2012. “Transforming Conflict: Trust, Empathy, and Dialogue." International Journal of Peace Studies 17(2):33-55.

Heider, Anne, and R. Stephen Warner. 2010. "Bodies in Sync: Interaction Ritual Theory Applied to Sacred Harp Singing." Sociology of Religion 71(1):76-97.

Heinskou, Marie Bruvik, and Lasse Suonpera Liebst. 2016. "On the Elementary Neural Forms of Micro-Interactional Rituals: Integrating Autonomic Nervous System Functioning Into Interaction Ritual Theory." Sociological Forum 31(2):354-76.

Herz, John H. 1959. International Politics in the Atomic Age. New York: Columbia University Press.

Hess, Ursula, Stephanie Houde, and Agneta Fischer. 2014. "Do We Mimic What We See or What We Know?" In Collective Emotions, edited by Christian von Scheve and Mikko Salmela, 94-107. Oxford: Oxford University Press.

Holmes, Marcus. 2013. "The Force of Face-to-Face Diplomacy: Mirror Neurons and the Problem of Intentions." International Organization 67(4):829-61.

Holmes, Marcus. 2014. "International Politics at the Brain's Edge: Social Neuroscience and a New 'Via Media'." International Studies Perspectives 15(2):209-28.

Holmes, Marcus. 2015. "Believing This and Alieving That: Theorizing Affect and Intuitions in International Politics.” International Studies Quarterly 59(4):706-20.

Holmes, Marcus. 2018. Face-to-Face Diplomacy: Social Neuroscience and International Relations. Cambridge, UK: Cambridge University Press.

Holmes, Marcus, and Keren Yarhi-Milo. 2017. "The Psychological Logic of Peace Summits: How Empathy Shapes Outcomes of Diplomatic Negotiations." International Studies Quarterly 61(1):107-22.

Horowitz, Michael C., Allan C. Stam, and Cali M. Ellis. 2015. Why Leaders Fight. New York: Cambridge University Press.

Hunt, Jonathan, and David Reynolds. 2016. “Geneva, Reykjavik, Washington, and Moscow 1985-8." In Transcending the Cold War: Summits, Statecraft, and the Dissolution of Bipolarity in Europe, 19701990, edited by Kristina Spohr and David Reynolds, 151-80. Oxford, UK: Oxford University Press.

Hutchison, Emma, and Roland Bleiker. 2014. "Theorizing Emotions in World Politics." International Theory 6(3):491-514.

Ickes, William, Renee Holloway, Linda L. Stinson, and Tiffany Graham Hoodenpyle. 2006. "SelfMonitoring in Social Interaction: The Centrality of Self-Affect." Journal of Personality 74(3):659-84.

Jaques, Natasha, Daniel McDuff, Yoo Lim Kim, and Rosalind Picard. 2016. "Understanding and Predicting Bonding in Conversations Using Thin Slices of Facial Expressions and Body Language." In Intelligent Virtual Agents, edited by David Traum, William Swartout, Peter Khooshabeh, Stefan Kopp, Stefan Scherer, and Anton Leuski. Vol. 10011, 64-74. Cham: Springer International Publishing.

Jaques, Natasha, Yoo Lim Kim, and Rosalind Picard. 2016. "Personality, Attitudes, and Bonding in Conversations." In Intelligent Virtual Agents, edited by David Traum, William Swartout, Peter Khooshabeh, Stefan Kopp, Stefan Scherer, and Anton Leuski. Vol. 10011, 378-82. Cham: Springer International Publishing.

Jeffery, Renée. 2014. Reason and Emotion in International Ethics. Cambridge: Cambridge University Press. Jervis, Robert. 1976. Perception and Misperception in International Politics. Princeton University Press.

Jervis, Robert. 1989. The Logic of Images in International Relations. New York: Columbia University Press. Jervis, Robert. 2013. “Do Leaders Matter and How Would We Know?” Security Studies 22(2):153-79.

Jönsson, Christer, and Martin Hall. 2005. Essence of Diplomacy. Basingstoke: Palgrave Macmillan.

Jordan, Judith V. 1986. “The Meaning of Mutuality.” Working Paper Series, No. 23. Wellesley, MA: Center for Research on Women - Stone Center. https://www.wcwonline.org/pdf/previews/preview_23sc.pdf

Karpukhin, Sergei. 2013. "At G20, No Warming of Chilly U.S.-Russia Ties." The Moscow Times, 9 September 2013. http://themoscowtimes.com/news/at-g20-no-warming-of-chilly-us-russia-ties-27472.

Kelley, Harold H., Ellen Berscheid, Andrew Christensen, John H. Harvey, Ted L. Huston, George Levinger, Evie McClintock, Letitia Anne Peplau, and Donald R. Peterson. 1983. Close Relationships. New York, NY: W.H. Freeman. 
Kempe, Frederick. 2011. Berlin 1961: Kennedy, Khrushchev, and the Most Dangerous Place on Earth. New York: Penguin.

Kennedy, John Fitzgerald. 1961. The Strategy of Peace. New York: Popular Library.

Keohane, Robert Owen. 1984. After Hegemony: Cooperation and Discord in the World Political Economy. Princeton, NJ: Princeton University Press.

Kertzer, Joshua D., and Dustin Tingley. 2018. "Political Psychology in International Relations: Beyond the Paradigms." Annual Review of Political Science 21(1):319-39.

Kohut, H. 1966. "Forms and Transformations of Narcissism." Journal of the American Psychoanalytic Association 14(2):243-72.

Liebst, Lasse Suonpera. 2019. "Exploring the Sources of Collective Effervescence: A Multilevel Study." Sociological Science 6:27-42.

Ling, Richard. 2010. New Tech, New Ties: How Mobile Communication is Reshaping Social Cohesion. Cambridge, MA: MIT Press.

Matlock, Jack F. 2005. Reagan and Gorbachev: How the Cold War Ended. New York: Random House Trade Paperbacks.

Mcconaughey, Meghan, Paul Musgrave, and Daniel H. Nexon. 2018. "Beyond Anarchy: Logics of Political Organization, Hierarchy, and International Structure.” International Theory 10(2):181-218.

McDermott, Rose. 2004. "The Feeling of Rationality: The Meaning of Neuroscientific Advances for Political Science." Perspectives on Politics 2(4):691-706.

McFarland, Daniel A., Dan Jurafsky, and Craig Rawlings. 2013. "Making the Connection: Social Bonding in Courtship Situations." American Journal of Sociology 118(6):1596-649.

Meerts, Paul, and Sinisa Vukovic. 2015. "Reputation and Egotiation: The Impact of Self-Image on the Negotiator." In Emotion in Group Decision and Negotiation, edited by Bilyana Martinovsky, 73-99. Amsterdam: Springer.

Mercer, Jonathan. 2005. "Rationality and Psychology in International Politics." International Organization 59(1):77-106.

Mercer, Jonathan. 2010. “Emotional Beliefs.” International Organization 64(1):1-31.

Mercer, Jonathan. 2014. "Feeling like a State: Social Emotion and Identity." International Theory 6(3):515-35.

Morris, Edmund. 2000. Dutch: A Memoir of Ronald Reagan. London, UK: HarperCollins.

Nguyen, David, and John Francis Canny. 2009. "More than Face-to-Face: Empathy Effects of Video Framing." Conference: Proceedings of the 27th International Conference on Human Factors in Computing Systems, CHI 2009, Boston, MA.

Nicolson, Sir Harold. 1939. Diplomacy. Harcourt Brace.

Parajon, Eric. 2019. "Maintaining Continuity of Relationships: The Benefits of Video Communication Technology.” Global Research Institute (William \& Mary), 2019 International Studies Association Conference Paper.

Pedwell, Carolyn. 2014. Affective Relations. London: Palgrave Macmillan.

Pentland, Alex. 2008. Honest Signals: How They Shape Our World. Cambridge, MA: MIT Press.

Pouliot, Vincent. 2010. International Security in Practice: The Politics of NATO-Russia Diplomacy. Cambridge: Cambridge University Press.

Pouliot, Vincent. 2016. International Pecking Orders: The Politics and Practice of Multilateral Diplomacy. New York: Cambridge University Press.

Rathbun, Brian C. 2014. Diplomacy's Value: Creating Security in 1920s Europe and the Contemporary Middle East. Ithaca, NY: Cornell University Press.

Reagan, Ronald. 1990. An American Life: The Autobiography. New York: Simon and Schuster.

Reynolds, David. 2009. Summits: Six Meetings That Shaped the Twentieth Century. Basic Books.

Ringmar, Erik. 2018. “What are Public Moods?” European Journal of Social Theory 21(4):453-69.

Ritter, Kathrin, Isabel Dziobek, Sandra Preißler, Anke Rüter, Aline Vater, Thomas Fydrich, Claas-Hinrich Lammers, Hauke R. Heekeren, and Stefan Roepke. 2011. "Lack of Empathy in Patients with Narcissistic Personality Disorder.” Psychiatry Research 187(1):241-47.

Rosenau, James N. 1966. "Pre-Theories and Theories of Foreign Policy." In Approaches to Comparative and International Politics, 27-92. Evanston, IL: Northwestern University Press.

Ross, Andrew A.G. 2014. Mixed Emotions: Beyond Hatred in International Conflict. Chicago: Chicago University Press. 
Rossner, Meredith. 2011. "Emotions and Interaction Ritual: A Micro Analysis of Restorative Justice." The British Journal of Criminology 51(1):95-119.

Sasley, Brent E. 2010. "Affective Attachments and Foreign Policy: Israel and the 1993 Oslo Accords." European Journal of International Relations 16(4):687-709.

Saunders, Elizabeth N. 2011. Leaders at War: How Presidents Shape Military Interventions. Ithaca, NY: Cornell University Press.

Sending, Ole Jacob, Vincent Pouliot, and Iver B. Neumann (eds). 2015. Diplomacy and the Making of World Politics. Cambridge: Cambridge University Press.

Sharp, Paul. 2009. Diplomatic Theory of International Relations. Cambridge: Cambridge University Press.

Shifrinson, Joshua R. Itzkowitz. 2016. "Deal or No Deal? The End of the Cold War and the U.S. Offer to Limit NATO Expansion.” International Security 40(4):7-44.

Shilling, Chris. 2003. The Body and Social Theory. London: SAGE.

Shilling, Chris, and Philip A. Mellor. 1998. "Durkheim, Morality and Modernity: Collective Effervescence, Homo Duplex and the Sources of Moral Action." The British Journal of Sociology 49(2):193-209.

Solomon, Ty, and Brent J. Steele. 2017. "Micro-Moves in International Relations Theory." European Journal of International Relations 23(2):267-91.

Stephens, John Paul, Emily Heaphy, and Jane E. Dutton. 2011. "High Quality Connections." In The Oxford Handbook of Positive Organizational Scholarship, edited by Gretchen M. Spreitzer and Kim S. Cameron. New York: Oxford University Press.

Streeck, Jurgen, Charles Goodwin, and Curtis LeBaron. 2011. Embodied Interaction: Language and Body in the Material World. New York: Cambridge University Press.

Tonkonoff, Sergio. 2017. From Tarde to Deleuze and Foucault: The Infinitesimal Revolution. New York: Palgrave Macmillan.

Trager, Robert F. 2017. Diplomacy: Communication and the Origins of International Order. Cambridge University Press.

Turner, Jonathan H. 2002. Face to Face. Stanford, CA: Stanford University Press.

van der Zeeuw, Alex, Laura Keesman, and Don Weenink. 2018. "Sociologizing with Randall Collins: An Interview about Emotions, Violence, Attention Space and Sociology." European Journal of Social Theory 21(2):245-59.

Waltz, Kenneth. 1959. Man, the State and War. New York: Columbia University Press.

Waltz, Kenneth. 1979. Theory of International Politics. New York: McGraw Hill.

Wendt, Alexander. 1992. "Anarchy Is What States Make of It: The Social Construction of Power Politics." International Organization 46(2):391-425.

Wendt, Alexander. 1999. Social Theory of International Politics. Cambridge: Cambridge University Press. Wheeler, Nicholas J. 2013. "Investigating Diplomatic Transformations." International Affairs 89(2):477-96.

Wheeler, Nicholas J. 2018. Trusting Enemies: Interpersonal Relationships in International Conflict. Oxford, UK: Oxford University Press.

Wong, Seanon. 2016. "Emotions and the Communication of Intentions in Face-to-Face Diplomacy." European Journal of International Relations 22(1):144-67.

Yarhi-Milo, Keren. 2014. Knowing the Adversary: Leaders, Intelligence, and Assessment of Intentions in International Relations. Princeton, NJ: Princeton University Press.

Yarhi-Milo, Keren. 2018. Who Fights for Reputation? The Psychology of Leaders in International Conflict. Princeton, NJ: Princeton University Press.

Cite this article: Holmes, M., Wheeler, N. J. 2020. “Social bonding in diplomacy." International Theory 12, 133-161, doi:10.1017/S1752971919000162 